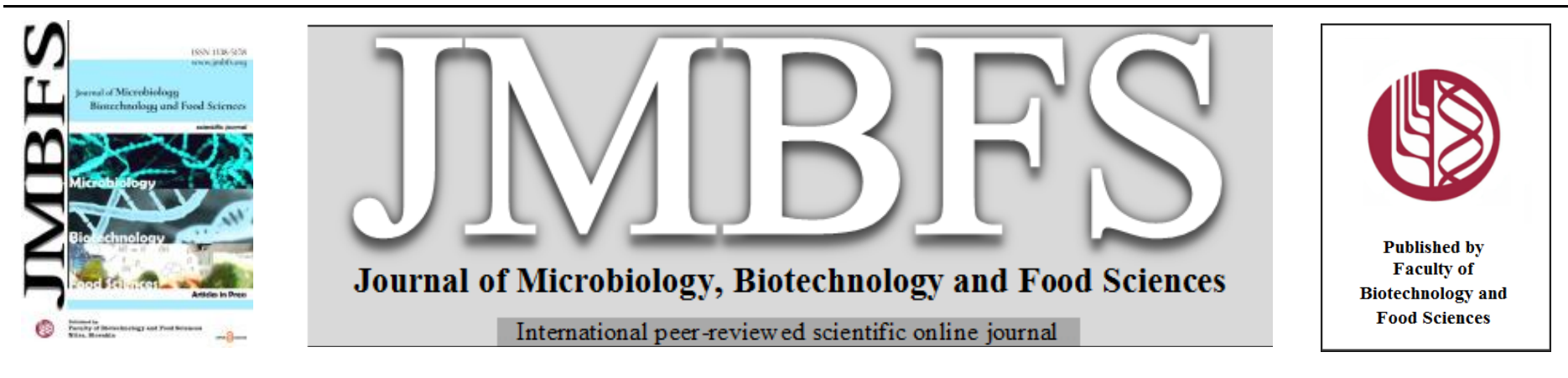

\title{
EVALUATION OF PHYSIO-CHEMICAL CHARACTERISTICS AND ACRYLAMIDE CONTENT IN CRISP FRIED DOUGH WAFERS MADE FROM NIXTAMALIZED PEARL MILLET
}

\author{
Supriya Pandey ${ }^{l}$, Rakesh Ghosh ${ }^{l}$, Deodatt Suryawanshi ${ }^{2}$, Roji Waghmare* Wl, $^{3}$ \\ $\operatorname{Address(es):~}$ \\ ${ }^{1}$ Food Science and Technology, School of Biotechnology and Bioinformatics, D. Y. Patil University, Navi Mumbai, India. \\ ${ }^{2}$ Department of Community Medicine, Trichy SRM Medical College Hospital \& Research Centre, Tiruchirappalli, Tamil Nadu-621105, India \\ ${ }^{3}$ Department of Food Engineering, College of Food Technology, Dr. Panjabrao Deshmukh Krishi Vidyapeeth, Yavatmal, Maharashtra-445001, India
}

*Corresponding author: rosewaghmare@gmail.com

https://doi.org/10.55251/jmbfs.3186

\section{ARTICLE INFO}

Received 26. 5. 2020

Revised 31. 1. 2022

Accepted 7. 2. 2022

Published 1. 6. 2022

Regular article

open $\odot$ access

\begin{abstract}
Pearl millet (Pennisetum glaucum), a drought tolerant crop belonging to the family Poaceae is an important type of millet. It is a sturdy plant that can sustain adverse growing conditions. It is rich in vitamins, minerals, oil and phytochemicals. The phytates or phytic acid present acts as antinutritional factor which bind to the proteins and minerals thereby reducing the digestibility and bioavailability of the proteins, carbohydrates and minerals. In the following study, nixtamalization, a process widely used for the treatment of maize, is being used on the millet to lower the antinutritional properties of the millet. The grain was cooked at $95^{\circ} \mathrm{C}$ with varying lime concentration $(0.5 \%, 1.0 \%, 1.5 \%, 2.0 \%)$ while keeping the cooking time (30 min) and steeping time ( 2 hours) constant. Product (crisp fried dough wafers) was made from the milled nixtamalized flour and different physio-chemical parameters and acrylamide content of the crisp fried dough wafer was analysed. The product made from flour treated with $1.5 \%$ lime showed the best results and overall acceptability. This research could be beneficial for increasing the utilization of pearl millet in different parts of the world especially in under developed countries as a health food. Also, the phytochemicals of pearl millet have various health benefits and this study can be used to increase their concentration and thereby promote the use of pearl millet for enrichment of various food products.
\end{abstract}

\section{INTRODUCTION}

Nixtamalization or alkaline cooking is a method where alkaline solutions are used for the treatment of whole grains (Gaytán-Martínez et al. 2017). In Central America and some parts of Mexico this method is widely used for the treatment of corn kernels (Boniface and Gladys, 2011; Rendón-Villalobos et al. 2009). Lime wood-ash and lye are the common agents used for nixtamalization process. During the process there are physical, chemical and structural changes observed in the whole grains (Owusu-Kwarteng and Akabanda, 2013). The calcium content and the bioavailability of niacin increases with nixtamalization. The treatment helps in the reduction of aflatoxin and improves the protein quality in the final product (Owusu-Kwarteng and Akabanda, 2013; Rajeswari et al. 2015). The process helps in improving the flavour and aroma of the grain (Sefa-Dedeh et al. 2004) The treatment helps in increasing the protein digestibility of the grain, makes the grains softer thereby making it easier to ground into flour (Boniface and Gladys, 2011).

Pearl millet (Pennisetum glaucum) also known as Bajra is one of the most important type of millet. It is a drought tolerant crop belonging to the family Poaceae (Abdel- Hafez et al. 2017; Adebiyi et al. 2016). It is widely cultivated in Indian and South African subcontinents (Sandhu and Siroha, 2017). It can grow well in difficult conditions like low fertile soil, high temperature condition and soil with high salinity. Due to its high tolerance to adverse growing conditions pearl millet can grow in areas where other cereals like wheat, corn, sorghum fail to grow (Shaikh et al. 2017). Compared to other cereal crops it has a higher oil content (Jain and Bal, 1997). It is a rich source of protein, dietary fibre, starch, phytochemicals (tannins, phytic acid, ferulic acid and other phenolic compounds), vitamins like vitamin $\mathrm{E}$, vitamin $\mathrm{K}$ and $\mathrm{B}$ complex vitamin (Thiamine, Riboflavin, Niacin, Vitamin B6, Folate and Pantothenic acid) (Lestienne et al. 2005; Jain and Bal, 1997). It is a well known source of calcium, iron and zinc and essential amino acids (Lestienne et al. 2007). Pearl millet consists of antinutritional factors in the form of condensed tannins, phytates, etc which bind to the proteins and minerals thereby reducing the digestibility and bioavailability of the proteins, carbohydrates and minerals (Gaytán-Martínez et al., 2017; Lestienne et al., 2007).

International Agency for Research on Cancer (IARC) has classified acrylamide as a probable carcinogen. Acrylamide is chiefly found in fried product such as potato French fries (Abdul Hamid et al., 2018). The formation of acrylamide is associated with Maillard reaction (Salazar et al., 2014). The presence of carbonyl compounds or similar groups which can react with asparagine amino acid and form
Schiff base are responsible for acrylamide formation (Salazar et al., 2014; Hidalgo et al., 2009). Various chemical agents such as asparaginase, acids, divalent actions, phospholipids and some amino acids that are used as food additives are found to be reducing the formation of acrylamide in thermally processed foods (Salazar et al., 2014; Kalita and Jayanty, 2013).

The purpose of this study were to evaluate the effect of nixtamalization on fried food prepared from nixtamalized pearl millet flour and to analyse the changes associated with the food product in terms of its proximate composition, antioxidan scavenging activity, total polyphenol content, tannin content, colour analysis, TPA and detection of acrylamide in the crisp fried dough wafers.

\section{MATERIAL AND METHODS}

\section{Materials}

Raw pearl millet was procured from local supermarket. Calcium oxide of analytical grade was purchased from a local dealer. Gallic acid, ascorbic acid, vanillin, Folin Ciocalteu reagent and 2,2-diphenyl-1-picrylhydrazyl (DPPH) was purchased from Sisco Research Laboratory Pvt. Ltd. (SRL). Catechin was purchased from Sigma Aldrich. Reagents like methanol and $\mathrm{HCl}$ was purchased from Merck and Co. All the reagents and solvents used were of analytical grade.

\section{Methods}

\section{Nixtamalization of the grain}

Pearl millet was manually cleaned to remove damaged seeds or any debris. The grains were stored in a clean and dry environment until further use. These grains were cooked in lime solution of concentration $0.5 \%, 1.0 \%, 1.5 \%$ and $2.0 \%$ for a period of $30 \mathrm{~min}$ and steeped for 2 hours. The ratio of grain to water used for cooking of all the samples were $1: 3 \mathrm{w} / \mathrm{v}$. The cooking temperature were kept constant for all the samples i.e. $95^{\circ} \mathrm{C}$. After steeping, the nixtamalized grains were washed thoroughly to remove excess of lime and extraneous pericarp material Distilled water has been used for cooking and washing the grains throughout the experiment. The grains were dried in a tray drier at a temperature of $65 \pm 2{ }^{\circ} \mathrm{C}$ for 3 hours. Following this, the grains were pulverized using a disc attrition mill and sieved using $0.5 \mathrm{~mm}$ mesh screen. All the flours were stored in an air tight container 
and were kept away from direct sunlight at $37^{\circ} \mathrm{C}$ temperature until samples were prepared.

\section{Preparation of crisp fried dough wafers}

For preparation of crisp fried dough wafers, nixtamalized pearl millet flour was rehydrated with enough water and mixed with a small amount of clarified butter and salt to make a dough of proper consistency respectively. The dough is shaped into thin disc of $1 \mathrm{~mm}$ in thickness and having a diameter of $4 \mathrm{~cm}$. These discs were deep fried for $1 \mathrm{~min}$ on each side in rice bran oil at a temperature of $180^{\circ} \mathrm{C}$. After frying the crisp fried dough wafers were cooled on an absorbent paper towel and were tested for proximate composition, antioxidant scavenging activity, total phenolic content, tannin estimation, colour, texture profile analysis and presence of acrylamide. They were stored in clean air tight container until further use.

\section{Proximate analysis}

All the samples were analysed for moisture content, ash content, calcium content, protein content and total fat content. Total ash content was determined by method 08-03.01 (AACC, 2000), calcium content was estimated using 983.35 method of (AOAC, 1997), protein content was determined using the method of (Kisan et al. 1973), and total fat was estimated by (AACC, 2000). All analysis were performed in triplicate.

\section{Extract preparation}

Methanolic extracts of the fried samples were prepared using the method reported by (Gaytán-Martínez et al., 2017) with some slight modification. About 1g of fried sample were mixed with $10 \mathrm{ml}$ of methanol. The mixture was kept away from direct sunlight and stirred in a magnetic stirrer at an rpm of 450 for $30 \mathrm{~min}$ at $25^{\circ} \mathrm{C}$. The extracted sample along with the residue was then vortexed and then centrifuged at 3000 RPM for 6 min. The supernatant was collected and stored at $20^{\circ} \mathrm{C}$ until further use. These extracts were further used for determination of antioxidant activity, total phenolic content and tannin content. All the results were an average of triplicate readings.

\section{Antioxidant scavenging activity using DPPH+}

he free radical scavenging activity was measured using a stable radical 2,2 diphenyl-1-picrylhydrazyl (DPPH) according to the method reported by with some modification. A total of $100 \mu \mathrm{L}$ of methanolic extract were mixed with $900 \mu \mathrm{L}$ of freshly prepared $60 \mu \mathrm{M}$ DPPH solution. The reaction mixtures were vortexed and placed in dark for $30 \mathrm{~min}$ at room temperature. The optical density was measured at $515 \mathrm{~nm}$ using a UV-Vis spectrophotometer (UV-1700 Pharma Spec, Shimadzu). All the results were an average of triplicate readings. The inhibition percentage was calculated against a reagent blank and the results were expressed.

\section{Estimation of phenolics by Folin-Ciocalteu assay}

The total phenolic content of all the methanolic extracts were determined by Folin Ciocalteu method as mentioned by (Samshuddin et al., 2015) with some slight modification. The reaction was initiated by oxidizing $100 \mu \mathrm{L}$ of sample extract with $200 \mu \mathrm{L}$ of freshly prepared Folin Ciocalteu reagent $(10 \%)$ and $800 \mu \mathrm{L}$ of sodium carbonate $(700 \mathrm{mM})$. This mixture was kept in dark at room temperature for $30 \mathrm{~min}$. The absorbance was measured at $765 \mathrm{~nm}$ using a UV-Vis spectrophotometer (UV-1700 Pharma Spec, Shimadzu). The results were expressed as $\mu \mathrm{g}$ of gallic acid equivalents per gram of sample ( $\mu \mathrm{gGAE} / \mathrm{g})$. All the results were an average of triplicate readings.

\section{Estimation of tannins}

Tannin content were determined using a method reported by (Gaytán-Martínez et al., 2017). Methanolic extract $(200 \mu \mathrm{L})$ were mixed with $800 \mu \mathrm{L}$ vanillin reagent ( $0.5 \%$ vanillin, $4 \% \mathrm{HCl}$ in methanol) and kept for $20 \mathrm{~min}$. The absorbance of the mixtures were measured at 492nm using a UV-Vis spectrophotometer (UV-1700 Pharma Spec, Shimadzu). The tannins were expressed as $\mu g(+)-$ catechin equivalent per gram of sample $(\mu \mathrm{g} \mathrm{CAE} / \mathrm{g})$. All the results were an average of triplicate readings.

\section{Colour analysis of crisp fried dough wafers}

The colour of all the crisp fried dough wafers were analyzed using a Hunter Lab Colorimeter (ColorFlex EZ, Hunter Lab, Reston USA). L*, a* and b* were the three colour coordinates that were examined, where $\mathrm{L}^{*}$ represents the lightness or darkness, $a^{*}$ represents redness or greenness and $b^{*}$ represents yellow or blue. All the results were an average of the triplicate readings.

\section{Texture Profile Analysis (TPA)}

Texture profile of all the fried samples were analysed using CT3 texture analyzer (probe: needle probe [TA9, 20mm L]; pre-test speed: $1.00 \mathrm{~mm} / \mathrm{s}$, test speed: 0.50 $\mathrm{mm} / \mathrm{s}$, post-test speed: $0.50 \mathrm{~mm} / \mathrm{s}$; load cell: $10 \mathrm{~kg}$ ). The resistance of the material to the applied forces is measured by a calibrated load cell and the results were expressed in either grams or Newton (Rana et al., 2018; Ghosh et al., 2017; Yi et al., 2016). The software used for all the results was Texture Probe CT Software.

Fourier Transmission - Infrared (FTIR) Spectroscopy of crisp fried dough wafers

Attenuated total reflection (ATR) infrared spectra of the samples were obtained using a FTIR Spectrophotometer (FTIR-8400S, Shimadzsu). Background spectra of the instrument were collected before mounting the samples $(0.1 \mathrm{~g}$ of each milled sample) on the instrument. All the spectra were recorded with characteristic peak in wave numbers from 500 to $40001 / \mathrm{cm}$. All spectra measurement were carried out room temperature.

\section{Statistical analysis}

All data were expressed as means \pm standard errors of triplicate measurements and analyzed by SPSS for Windows (ver. 16.0). One-way analyses of variance (ANOVA) were carried out to test significant differences $(\mathrm{p} \leq 0.05)$. Mean and standard deviation were computed using Microsoft Excel 2010.

\section{RESULTS AND DISCUSSION}

\section{Proximate analysis}

Proximate composition of crisp fried dough wafers made from nixtamalized pear millet flour is shown in Table 1. The ash content for the samples was found to be increasing from $0.5 \%$ lime concentration to $2.0 \%$ lime concentration. The ash content for the treated sample ranged in $1.86 \%-2.86 \%$ while the ash content for the untreated sample was $1.56 \%$. It can be said that there was an increase in ash content of the sample. The moisture content of the sample is found to be in the range of 2.95-3.15\%. During nixtamalization calcium oxide gets incorporated into the grain thereby increasing the ash content of the flour and ultimately the product made from the flour (Salazar et al., 2014; Villada et al., 2017). The calcium content for the samples were also found to be in an increasing order from 20.24 $\mathrm{mg} / \mathrm{g}$ for $0.5 \%$ lime concentration to $28.09 \mathrm{mg} / \mathrm{g}$ for $2.0 \%$ lime concentration. The calcium content for untreated samples were a low value of $16.08 \mathrm{mg} / \mathrm{g}$. The increase in the calcium content for the treated sample were a result of $\mathrm{Ca}^{+}$ions being absorbed into the grain during the lime cooking and steeping (OwusuKwarteng and Akabanda, 2013).

The influence of nixtamalization on the protein content was seen with a decrease in the protein content due to starch gelatinization (Obadina et al., 2016). The protein content of the untreated grain was estimated to be $9.73 \mathrm{~g} / 100 \mathrm{~g}$ and the protein in the treated samples ranged from $7.29-9.1 \mathrm{~g} / 100 \mathrm{~g}$. The decrease in the protein content is a result of heat treatment of the grain during alkaline cooking which resulted in the changes in the protein structure thereby improving protein digestibility and making it easy for absorption (Gomez et al., 1989). The decrease in the protein content can also be due to high temperature at the time of frying. Further studies need to be done upon the starch structure during nixtamalization. The fat content of the crisp fried dough wafers is responsible for the mouthfeel of the product and also has an effect on the sensorial characteristic of the product. An increase in the total fat content of the product were observed. The untreated sample shows a lower total fat content of $30.75 \mathrm{~g} / 100 \mathrm{~g}$. The total fat content of the treated sample ranged from 31.59 to $36.81 \mathrm{~g} / 100 \mathrm{~g}$. Thus there was an increase in the total fat content of the crisp fried dough wafer and this can be due to rapid loss of moisture during cooking. Xu and Kerr, 2012; Salazar et al., 2014 reported similar findings on maize.

Table 1 Proximate composition of crisp fried dough wafers made with nixtamalized pearl millet

\begin{tabular}{lccccc}
$\begin{array}{l}\text { Concentration of } \\
\text { Lime (\%) }\end{array}$ & $\begin{array}{c}\text { Moisture content } \\
(\boldsymbol{\%})\end{array}$ & Ash Content $(\boldsymbol{\%})$ & $\begin{array}{c}\text { Calcium Content } \\
(\mathbf{m g} / \mathbf{g})\end{array}$ & $\begin{array}{c}\text { Protein Content } \\
(\mathbf{g} / \mathbf{1 0 0 g})\end{array}$ & $\begin{array}{c}\text { Total Fat Content } \\
(\mathbf{g} / \mathbf{1 0 0 g})\end{array}$ \\
\hline $\mathbf{0 \%}$ & $3.18 \pm 0.04^{\mathrm{a}}$ & $1.56 \pm 0.06^{\mathrm{a}}$ & $16.08 \pm 0.05^{\mathrm{a}}$ & $9.73 \pm 0.05$ & $30.7 \pm 0.05^{\mathrm{a}}$ \\
$\mathbf{0 . 5 0 \%}$ & $3.02 \pm 0.03^{\mathrm{b}}$ & $1.86 \pm 0.07^{\mathrm{b}}$ & $20.24 \pm 0.09^{\mathrm{b}}$ & $7.32 \pm 0.04^{\mathrm{b}}$ & $31.59 \pm 0.06^{\mathrm{b}}$ \\
$\mathbf{1 . 0 0 \%}$ & $3.07 \pm 0.05^{\mathrm{c}}$ & $2.1 \pm 0.02^{\mathrm{c}}$ & $21.72 \pm 0.07^{\mathrm{c}}$ & $9.1 \pm 0.08^{\mathrm{c}}$ & $33.46 \pm 0.06^{\mathrm{c}}$ \\
$\mathbf{1 . 5 0 \%}$ & $2.95 \pm 0.02^{\mathrm{d}}$ & $2.64 \pm 0.03^{\mathrm{d}}$ & $24.13 \pm 0.06^{\mathrm{d}}$ & $8.11 \pm 0.08^{\mathrm{d}}$ & $35.36 \pm 0.07^{\mathrm{d}}$ \\
$\mathbf{2 . 0 0 \%}$ & $3.04 \pm 0.09^{\mathrm{c}}$ & $2.86 \pm 0.08^{\mathrm{e}}$ & $28.09 \pm 0.04^{\mathrm{e}}$ & $7.29 \pm 0.09^{\mathrm{e}}$ & $36.81 \pm 0.07^{\mathrm{e}}$ \\
\hline
\end{tabular}

$*$ Different small letters following the values in same column indicate differences for each concentration of lime $(\mathrm{P}<0.05)$. 


\section{Influence on Antioxidant Scavenging Activity of $\mathrm{DPPH}^{+}$Radical}

The antioxidant activities of the methanolic extracts of the product was assayed against a basic free radical knowns as 2,2-diphenyl-1-pcrylhydrazyl $\left(\mathrm{DPPH}^{+}\right)$. The antioxidant scavenging activity of DPPH was evaluated using ascorbic acid as the standard antioxidant. In accordance with Table 2, there is an increase in the antioxidant scavenging activity of the nixtamalized samples. The increase in the activity can be seen from $0.5 \%$ lime treated sample exhibiting the antioxidan activity of $59.79 \%$ whereas that of $2.0 \%$ lime treated sample is $61.99 \%$. The highest antioxidant activity is seen from $1.5 \%$ of lime treated sample which is $62.89 \%$. The phenolic and tannin content in the grains are responsible for the antioxidant activity exhibited of the grain (Gaytán-Martínez et al., 2017). These phenolic compounds are usually found in a bound form in the grains where the form esterified bonds with the cell wall components of the whole cereal grains. Many physical and chemical processes such as alkaline hydrolysis, extrusioncooking, etc has been effective in liberating these bonds and turning the phenolics into a free form which in turn makes them available for the antioxidant activity (Acosta-Estrada et al., 2014). The release of these antioxidant is greatly influenced by higher level of alkaline agent and temperature used during cooking (Oufnac et al., 2007).

\section{Effect on Total Phenolic Content}

According to Table 2, significant variation in the total phenolic content can be seen. Decrease in the total phenolic content of the nixtamalized crisp fried dough wafers was observed. The total phenolic content of the sample made from nonnixtamalized pearl millet was found to be $42.51 \mu \mathrm{g}$ GAE/g whereas the total phenolic content for the treated sample ranged from 6.64 to $40.04 \mu \mathrm{g}$ GAE $/ \mathrm{g}$. At lime concentration of $0.5 \%$ the total phenolic content was $40.04 \mu \mathrm{g} \mathrm{GAE} / \mathrm{g}$. The decrease in the content was observed with an increase in the lime concentration. This effect is because of the lime concentration and the steeping time (GaytánMartínez et al., 2017). Pearl millet consists of phenolic compounds situated in the pericarp, which gets removed from the grain at the time of cooking and steeping. This leads to the reduction of total phenols in the treated grains (Adetunji et al. 2015). Rajeswari et al. (2015) observed redcution in free, bound and total phenolic content in foxtail millet afer tratment with alkanine solution. It was found in this study that these reductions increases with alkaline concentration. In the alkaline environment some molecular structural changes of the phenolic compounds are also observed leading to disruption of these compounds

\section{Effect on Tannin Content}

Tannin content of the nixtamalized crisp fried dough wafers decreases as the lime concentration is increased (Table 2). The tannins in the untreated sample is higher $74 \mu \mathrm{g} \mathrm{CAE} / \mathrm{g}$ than that in the nixtamalized samples. The tannins in the nixtamalized sample range from $5.08 \mu \mathrm{g} \mathrm{CAE} / \mathrm{g}$ to $3.004 \mu \mathrm{g} \mathrm{CAE} / \mathrm{g}$. The process was successful in lowering the tannin content of the final finished product. Tannins in the cerea are polyphenolic in nature and they exhibit antinutritional properties, but many tannins are anti-nutritional factors. They are known to form complex bonds with divalent cations and proteins thereby making them insoluble for digestion. Hence they reduce the availability of divalent cations and proteins in the body by making them escape the intestinal absorption and are excreted (Lestienne et al., 2005) This results in deficiencies. In nixtamalization, the use of high temperature at the time of cooking leads to the removal of pericarp and saturates the tannins content of the treated cereal (Gaytán-Martínez et al., 2017). Ocheme, Oludamilola and Gladys (2010) have reported similar studies in which thay have observed a significant reduction in tannin content with lime concentration.

Table 2 Effect of nixtamalization on antioxidant scavenging activity of $\mathrm{DPPH}^{+}$radical, total phenolic content, tannin content of crisp fried dough wafers

\begin{tabular}{|c|c|c|c|c|c|}
\hline \multirow{2}{*}{ Parameter } & \multicolumn{5}{|c|}{ Concentration of Lime $(\%)$} \\
\hline & $0 \%$ & $0.50 \%$ & $1.00 \%$ & $1.50 \%$ & $2.00 \%$ \\
\hline Antioxidant Scavenging Activity (\%) & $51.04 \pm 0.05^{\mathrm{a}}$ & $59.79 \pm 0.06^{\mathrm{b}}$ & $60.3 \pm 0.09^{c}$ & $62.89 \pm 0.08^{\mathrm{d}}$ & $61.99 \pm 0.08^{\mathrm{e}}$ \\
\hline Total Phenolic Content ( $\mu \mathrm{g}$ GAE/g) & $42.51 \pm 0.08^{\mathrm{a}}$ & $40.04 \pm 0.06^{\mathrm{b}}$ & $28.63 \pm 0.06^{\mathrm{c}}$ & $26.22 \pm 0.09^{d}$ & $6.64 \pm 0.08^{\mathrm{e}}$ \\
\hline Tannin Content ( $\mu \mathrm{g}$ CAE/g) & $7.44 \pm 0.06^{\mathrm{a}}$ & $5.08 \pm 0.07^{\mathrm{b}}$ & $4.27 \pm 0.09^{\mathrm{c}}$ & $3.72 \pm 0.07^{\mathrm{d}}$ & $3.05 \pm 0.04^{\mathrm{e}}$ \\
\hline
\end{tabular}

*Different small letters following the values in same row indicate differences for each attribute $(\mathrm{P}<0.05)$.

\section{Influence on Colour and Texture}

The effect of colour was determined by monitoring the changes in $\mathrm{L}^{*}, \mathrm{a}^{*}$ and $\mathrm{b}^{*}$ values of the crisp fried dough wafers. Colour is considered as one of the most important parameter which helps in determining the acceptability of fried products. The $\mathrm{L}^{*}$ value represents darkness when low and lightness when high. As observed in Table 3, $\mathrm{L}^{*}$ value of the product was lower which gave the product a darker hue. The $a^{*}$ and $b^{*}$ values of the product was lower than the untreated sample signifying a change in the colour. There are various factors that have an effect on the colour of the final product. These factors include cooking time, temperature, mineral content, etc. Lovera et al., (2014) reported similar finding that increase in the calcium content led to a darker finished product.

The texture of the food is one of the important parameter that affects the overal acceptability of the food product. It is characterised by hardness, adhesiveness, fracturability, cohesiveness, springiness, chewiness and gumminess. Hardness of the product can be defined as resistance of a material to deformation, indentation or penetration by means such as abrasion, drilling, impact, scratching or wear. It can be affected by various factors such as cooking time, cooking temperature, moisture absorption to name a few. Increase in the lime concentration of the crisp fried dough wafers, increases the hardness of the product. Properties such as fracturability and springiness also increases with the increase in the lime concentration. The increase in the fracturability and springiness is due to the increase in the firmness or rigidity of the product. Similar findings were reported by Rana et al., (2018) for jackfruit. The increase in the rigidity of the product can also be due to the increase in the calcium content of the nixtamalized grain (Lovera et al., 2014). Colour and texture were greatly improved with nixtamalization, perhaps due to the removal of extraneous pericarp materials during washing after lime cooking and soaking. Hydration of the millet grains during the alkaline cooking process leads to calcium ions incorporation into the millet grain. In these phases of cooking and steeping, hydration and partial gelling of the grain starches occur simultaneously, along with the diffusion of calcium ions, which determine the physicochemical and textural properties of the final product (Owusu-Kwarteng and Akabanda, 2013).

Table 3 Effect of nixtamalization on the $\mathrm{L}^{*}, \mathrm{a}^{*}, \mathrm{~b}^{*}$ values and texture of crisp fried dough wafers

\begin{tabular}{|c|c|c|c|c|c|}
\hline \multirow{2}{*}{ Properties } & \multicolumn{5}{|c|}{ Concentration of Lime \% } \\
\hline & $0 \%$ & $0.50 \%$ & $1.00 \%$ & $1.50 \%$ & $2.00 \%$ \\
\hline $\mathbf{L}^{*}$ & $46.03 \pm 2.43^{\mathrm{a}}$ & $34.51 \pm 2.24^{\mathrm{b}}$ & $40.54 \pm 2.48^{c}$ & $37.72 \pm 3.08$ & $40.15 \pm 1.08$ \\
\hline $\mathbf{a}^{*}$ & $10.58 \pm 0.86^{\mathrm{a}}$ & $4.9 \pm 0.32^{b}$ & $5.39 \pm 1.00^{c}$ & $5.1 \pm 0.46$ & $4.92 \pm 0.78$ \\
\hline $\mathbf{b}^{*}$ & $27.11 \pm 2.58^{\mathrm{a}}$ & $17.45 \pm 1.92^{\mathrm{b}}$ & $27.72 \pm 0.66^{\mathrm{c}}$ & $20.44 \pm 1.88$ & $21.55 \pm 1.38$ \\
\hline Hardness (N) & $2.97 \pm 0.05^{\mathrm{a}}$ & $5.67 \pm 0.07^{\mathrm{b}}$ & $5.68 \pm 0.03^{\mathrm{c}}$ & $8.44 \pm 0.42$ & $9.4 \pm 0.25$ \\
\hline Adhesiveness (J) & $0^{\mathrm{a}}$ & $0^{\mathrm{a}}$ & $0^{\mathrm{a}}$ & $0^{\mathrm{a}}$ & $0^{\mathrm{a}}$ \\
\hline Fracturability (N) & $3.53 \pm 0.35^{\mathrm{a}}$ & $5.64 \pm 0.1^{\mathrm{b}}$ & $5.65 \pm 0.06^{\mathrm{c}}$ & $3.08 \pm 0.12$ & $8.68 \pm 0.11$ \\
\hline Cohesiveness & $0^{\mathrm{a}}$ & $0.55 \pm 0.06^{\mathrm{b}}$ & $0.13 \pm 0.06^{\mathrm{c}}$ & $0.73 \pm 0.15$ & $0.53 \pm 0.09$ \\
\hline Springiness (mm) & $0^{\mathrm{a}}$ & $1.35 \pm 0.09^{\mathrm{b}}$ & $1.18 \pm 0.02^{\mathrm{c}}$ & $3.15 \pm 0.05$ & $3.69 \pm 0.04$ \\
\hline Gumminess (N) & $0^{\mathrm{a}}$ & $3.48 \pm 0.03^{\mathrm{b}}$ & $0.52 \pm 0.06^{\mathrm{c}}$ & $2.6 \pm 0.2$ & $5.77 \pm 0.1$ \\
\hline Chewiness (J) & $0^{\mathrm{a}}$ & $0^{\mathrm{a}}$ & $0^{\mathrm{a}}$ & $0^{\mathrm{a}}$ & $0^{\mathrm{a}}$ \\
\hline
\end{tabular}

*Different small letters following the values in same row indicate differences for each attribute $(\mathrm{P}<0.05)$.

\section{Detection of Acrylamide using FTIR}

An unsaturated amide commonly known as acrylamide is found in various thermally processed foods. At a high amount, it is considered as a neurotoxin and a potent carcinogenic. Foods containing high content of reducing sugars such as glucose and proteins specially rich in asparagine, amino acid, when heated at high temperature more than $170^{\circ} \mathrm{C}$ produce acrylamide (Gertz and Klostermann, 2002; Yadav et al., 2018). It consists of -NO group as the functional side chain. The FTIR spectrum for asymmetric N-O is from $1500-1600 \mathrm{~cm}^{-1}$ whereas for symmetric N-O the stretch is from $1300-1400 \mathrm{~cm}^{-1}$. Also the FTIR stretch for N$\mathrm{H}$ is found to be from $3350-3500 \mathrm{~cm}^{-1}$ (Pramanik et al., 2015). It can be observed in Figure 1a, 1c and 1d that all the interferograms showed a peak for either -NO 
group or for the N-H stretch. Since none of the interferograms showed peaks for both the stretch it can be concluded that the peaks observed are not because of acrylamide but are due to some protein moiety.In Figure $1 \mathrm{~b}$ and 1e no peaks were observed for either - NO group or for $\mathrm{N}-\mathrm{H}$ stretch, this can be due to protein denaturation in the treated samples. Further studies should be done to know better about the protein denaturation. The absence of acrylamide in the treated samples can be due to the increased mineral content of the product, since calcium content of the flour reduces the formation of Schiff's base responsible for the formation of acrylamide. Similar findings were reported by (Salazar et al., 2014) for maize tortilla. These authors observed a decrease of 52 and $36 \%$ in acrylamide content in tortilla chips, when a treatment of nixtamalization at lime concentrations of 1.5 and $2.0 \mathrm{~g} / 100 \mathrm{~g}$ respectively was given to corn flour.

\section{CONCLUSION}

Based on the study it can be concluded that the nixtamalization treatment was efficient in increasing the ash, calcium content of the product. Protein gelatinization was seen with the reduction in the protein content. Since pearl millet is high in fat, the total fat content of the product showed an increase. There was decrease in the tannin and polyphenolic content of the sample which indicated the reduction in the antinutritional factor of the millet altogether. The increase in antioxidant scavenging activity was associated with the decrease of the antinutritional factors viz., phytic acid in the case of pearl millet. The result obtained for antioxidant scavenging activity, polyphenols and tannins were interdependent. The treatment was done to decrease the antinutritional factor while retaining the maximum antioxidant activity. Considering all the parameters under analysis the product sample made with lime concentration of $1.5 \%$ showed the best result. It gave the best overall result and was more acceptable in terms of colour and texture. Thus it can be affirmed that nixtamalization can be used to increase the mineral content of the grains and which in turn helps in lowering the acrylamide of the final fried product. With nixtamalization these problems can be solved, and the bioavailability can be increased. Thus, the amount of condensed tannins in pearl millet can be significantly reduced with increase in the antioxidant activity of the grains. More studies should be conducted on the processing of cereal grains for reduction in their antinutritional property and retention of nutrients. In under developed countries pearl millet can be very effective in eradicating diseases caused due to low quality nutrition and thus the use of these underutilised grains should be highly promoted and consumed on a larger scale.

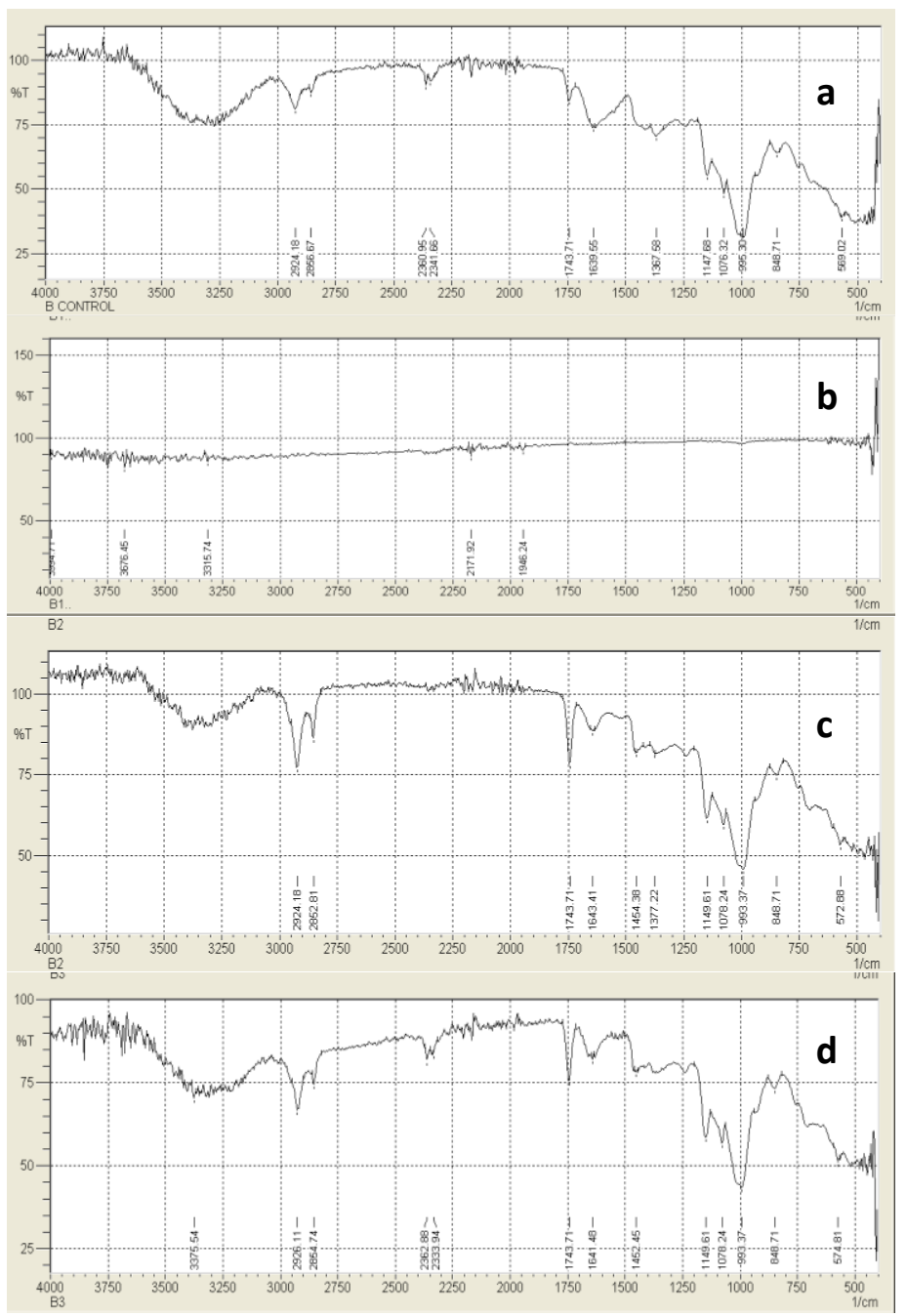

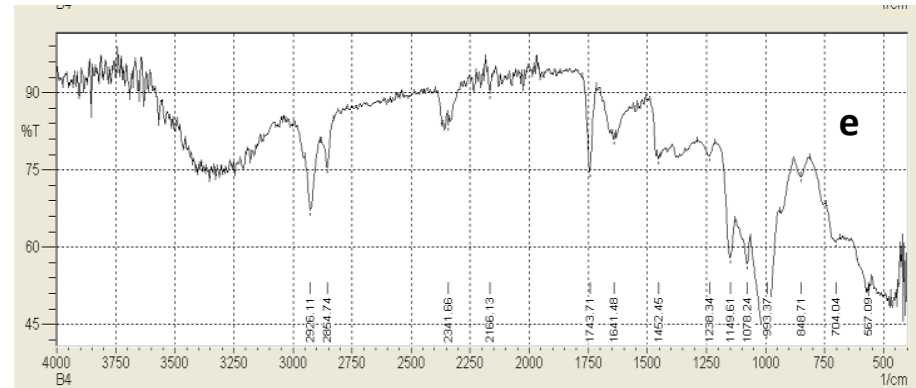

Figure 1 Effect of various a) $0 \%$ b) $0.5 \%$ c) $1 \%$ d) $1.5 \%$ and e) $2 \%$ lime concentrations on the acrylamide formation in crisp fried dough wafers

\section{REFERENCES}

AACC (2000), American Association of Cereal Chemists, Vasa, Methods https://doi.org/10.1094/AACCIntMethods.

Abdul Hamid, N., Omar, S. \& Sanny, M. (2018). Effect of thawing conditions and corresponding frying temperature profiles on the formation of acrylamide in French fries. Journal of the Saudi Society of Agricultural Sciences, 18(4), 396-400 https://doi.org/10.1016/j.jssas.2018.01.002

Abdel-Hafez, S.I., Abdel-Sater, M.A., Hussein, N.A., Abdul-Wahap A.L. \& Amery E. (2017). Fungal diversity associated with pearl millet pennisetum glaucum L.) Grains from taiz governorate, yemen and their amylase production. Journal of Microbiology, Biotechnology and Food Sciences, 7(2), 118-123. https://doi.org/10.15414/jmbfs.2017.7.2.118-123

Acosta-Estrada, B.A., Gutiérrez-Uribe, J. A. \& Serna-Saldívar, S.O. (2014). Bound phenolics in foods, a review. Food Chemistry, 152, 46-55. https://doi.org/10.1016/j.foodchem.2013.11.093

Adebiyi, J.A., Obadina A.O., Mulaba-Bafubiandi, A.F., Adebo, O.A., \& Kayitesi, E. (2016). Effect of fermentation and malting on the microstructure and selected physicochemical properties of pearl millet (Pennisetum glaucum) flour and biscuit. Journal of Cereal Science, 70, 132-139. https://doi.org/10.1016/j.jcs.2016.05.026 Adetunji, A.I., Duodu, K.G. \& Taylor, J.R.N. (2015). Inactivation of tannins in milled sorghum grain through steeping in dilute $\mathrm{NaOH}$ solution. Food Chemistry, 175, 225-232. https://doi.org/10.1016/j.foodchem.2014.11.102

AOAC (1997). Official Methods of Analysis of the Association of Official Analytical Chemists International, AOAC Arlington, VA, USA', Recovery studies, $17^{\text {th }}$ edn. Byrd Richmond, VA, (Type II), 969 https://doi.org/10.1021/ed038p431.2

Boniface, O.O. \& Gladys, M.E. (2011). Effect of alkaline soaking and cooking on the proximate, functional and some anti-nutritional properties of sorghum flour. AU Journal of Technology, 14(3), 210-216.

Gaytán-Martínez, M. et al. (2017). Effect of nixtamalization process on the content and composition of phenolic compounds and antioxidant activity of two sorghums varieties. Journal of Cereal Science, 77, 1-8. https://doi.org/10.1016/j.jcs.2017.06.014

Ghosh, P. et al. (2017). Physicochemical and Nutritional Characterization of Jamun (Syzygium Cuminii). Current Research in Nutrition and Food Science Journal, 5(1), 25-35. https://doi.org/10.12944/CRNFSJ.5.1.04

Gomez, M.H. et al. (1989). Changes in corn and sorghum during nixtamalization and tortilla baking. Journal of Food Science, 54(2), 330-336. https://doi.org/10.1111/j.1365-2621.1989.tb03074.x

Hidalgo, F.J., Delgado, R.M. \& Zamora, R. (2009). Degradation of asparagine to acrylamide by carbonyl-amine reactions initiated by alkadienals. Food Chemistry, 116(3), 779-784. https://doi.org/10.1016/j.foodchem.2009.03.020

Jain, R.K. \& Bal, S. (1997). Properties of pearl millet. Journal of Agricultural and Engineering Research, 66(2), 85-91. https://doi.org/10.1006/jaer.1996.0119 Kalita, D. \& Jayanty, S.S. (2013). Reduction of acrylamide formation by vanadium salt in potato French fries and chips. Food Chemistry, 138(1), 644-649. https://doi.org/10.1016/j.foodchem.2012.09.123

Kisan, M. et al. (1973). Method for determination of protein in Foods and Feeds. Indian Standard, (7219).

Lestienne, I. et al. (2005). Iron and Zinc in Vitro Availability in Pearl Millet Flours (Pennisetum glaucum) with Varying Phytate, Tannin, and Fiber Contents. Agriculture and Food chemistry, 53(8), 3240-3247. https://doi.org/10.1021/jf0480593

Lestienne, I. et al. (2007). Losses of nutrients and anti-nutritional factors during abrasive decortication of two pearl millet cultivars (Pennisetum glaucum). Food Chemistry, 100(4), 1316-1323. https://doi.org/10.1016/j.foodchem.2005.11.027 Lovera, N., Ramallo, L. \& Salvadori, V. (2014). Effect of processing conditions on calcium content, firmness, and color of papaya in syrup. Journal of Food Processing, 8. https://doi.org/10.1155/2014/603639

Obadina, A.O. et al. (2016). Nutritional and physico-chemical properties of flour from native and roasted whole grain pearl millet (Pennisetum glaucum [L.]R. Br.) Journal of Cereal Science, 70, 247-252. https://doi.org/10.1016/j.jcs.2016.06.005 
Ocheme, O.B., Oludamilola, O.O. \& Gladys, M.E. (2010). Effect of lime soaking and cooking (nixtamalization) on the proximate, functional and some antinutritional properties of millet flour. Technical Report, 14(2), 131-138.

Oufnac, D. S. et al. (2007). Extraction of antioxidants from wheat bran using conventional solvent and microwave-assisted methods, Cereal Chemistry, 84(2), $125-129$.

Owusu-Kwarteng, J. \& Akabanda, F. (2013). Applicability of nixtamalization in the processing of millet-based maasa, a fermented food in ghana. Journal of Food Research, 2(1), 59. https://doi.org/10.5539/jfr.v2n1p59

Rajeswari, J.R. et al. (2015). Effect of Alkaline Cooking on Proximate, Phenolics and Antioxidant activity of Foxtail Millet (Setaria italica). World Applied Sciences Journal, 33(1), 146-152. https://doi.org/10.5829/idosi.wasj.2015.33.01.8

Rana, S.S., Pradhan, R.C. \& Mishra, S. (2018). Variation in properties of tender jackfruit during different stages of maturity. Journal of Food Science and Technology. 55(6), 2122-2129. https://doi.org/10.1007/s13197-018-3127-9

Rendón-Villalobos, J. R. et al. (2009). Composition and characteristics of oil extracted from flaxseed-added corn tortilla. Food Chemistry, 117(1), 83-87. https://doi.org/10.1016/j.foodchem.2009.03.080

Salazar, R. et al. (2014). Effect of added calcium hydroxide during corn nixtamalization on acrylamide content in tortilla chips. LWT - Food Science and Technology, 56(1), 87-92. https://doi.org/10.1016/j.lwt.2013.10.046

Samshuddin, S. et al. (2015). Determination of total phenolic content and total antioxidant activity in locally consumed food stuffs in Moodbidri, Karnataka, India. Advances in Applied Science Research, 6(6), 99-102.

Sandhu, K.S. \& Siroha, A.K. (2017). Relationships between physicochemical, thermal, rheological and in vitro digestibility properties of starches from pearl millet cultivars. LWT - Food Science and Technology, 83, 213-224. https://doi.org/10.1016/j.lwt.2017.05.015

Sefa-Dedeh, S. et al. (2004). Effect of nixtamalization on the chemical and functional properties of maize. Food Chemistry, 86(3), 317-324. https://doi.org/10.1016/j.foodchem.2003.08.033

Shaikh, M., Ali, T.M. \& Hasnain, A. (2017). Utilization of chemically modified pearl millet starches in preparation of custards with improved cold storage stability. International Journal of Biological Macromolecules, 104, 360-366. https://doi.org/10.1016/j.ijbiomac.2017.05.183

Villada, J. A. et al. (2017). Study of the morphological, structural, thermal, and pasting corn transformation during the traditional nixtamalization process: From corn to tortilla. Journal of Food Engineering, 212, 242-251. https://doi.org/10.1016/j.jfoodeng.2017.05.034

Xu, S. \& Kerr, W.L. (2012). Comparative study of physical and sensory properties of corn chips made by continuous vacuum drying and deep fat frying. LWT - Food Science and Technology, 48(1), 96-101. https://doi.org/10.1016/j.lwt.2012.02.019 $\mathrm{Yi}$, J. et al. (2016). Influence of pre-drying treatments on physicochemical and organoleptic properties of explosion puff dried jackfruit chips. Journal of Food Science and Technology, 53(2), 1120-1129. https://doi.org/10.1007/s13197-015$\underline{2127-2}$ 